\title{
Hypovitaminosis D in 6 - 59-Month Children in the District of Parakou (Benin) in 2017
}

\author{
Alphonse Noudamadjo ${ }^{1}$, Joseph Agossou ${ }^{1}$, Julien Didier Adédémy¹, Falilatou Agbeille1, \\ Gérard Kpanidja1, Bakiou Babatoundé1, Gibril Abogbo² , Marcellin Kuassi Amoussou-Guénou² \\ ${ }^{1}$ Faculty of Medicine, University of Parakou, Parakou, Benin \\ ${ }^{2}$ Faculty of Health Science, University of Abomey-Calavi, Cotonou, Benin \\ Email: ^alphonse_ndama@yahoo.fr, agossoujoseph@gmail.com, kofadier@yahoo.fr,fmagbeille@yahoo.fr, \\ kpanidjagerard@yahoo.fr, elbakiou3@yahoo.com, gibralta85@yahoo.fr, agkuassimarcellin@yahoo.fr
}

How to cite this paper: Noudamadjo, A., Agossou, J., Adédémy, J.D., Agbeille, F., Kpanidja, G., Babatoundé, B., Abogbo, G. and Amoussou-Guénou, M.K. (2018) Hypovitaminosis D in 6 - 59-Month Children in the District of Parakou (Benin) in 2017. Open Journal of Pediatrics, 8, 94-105. https://doi.org/10.4236/ojped.2018.82012

Received: March 25, 2018

Accepted: April 15, 2018

Published: April 18, 2018

Copyright (C) 2018 by authors and Scientific Research Publishing Inc. This work is licensed under the Creative Commons Attribution International License (CC BY 4.0).

http://creativecommons.org/licenses/by/4.0/

\begin{abstract}
Introduction: Nutritional rickets is the visible tip of the iceberg formed by the diseases caused by hypovitaminosis. Vitamin D plasma is essentially influenced by the level of sunlight which is significant in Sub-Saharan Africa and in Benin. However, there are factors likely to impede endogenous production of that vitamin in children in our environment. This research work was conducted with the view to investigate hypovitaminosis $\mathrm{D}$ prevalence and associated factors in children aged 6 to 59 months in the District of Parakou in 2017. Methods: This research work was a cross-sectional study with prospective collection of data carried out in community in the District of Parakou in 2017. The study involved euthrophic and non-HIV infected children aged 6 to 59 months who did not benefit from vitamin D supplementation during the past three months. Vitamin D plasma concentration was obtained using "Radioimmunoassay" after cluster random sampling in accordance with WHO guidelines. According to Schwartz formula, nominal minimum sample size was 321. In this study, hypovitaminosis D was defined as a plasma level lower than $30 \mathrm{ng} / \mathrm{l}$. Data processing was carried out using softwares such as EPI INFO version 7.2 and SPSS 21 . Results: In total, 400 children were involved in the survey. Hypovitaminosis prevalence was $9.5 \%$ (38 out of 400 cases). In our research work, the factors associated with hypovitaminosis were child's age ( $\mathrm{p}$ $=0.0470)$, mother's age $(\mathrm{p}=0.0000)$, weaning age lower than 6 months $(\mathrm{p}=$ $0.0466)$ and mother's occupation out of direct sunlight $(\mathrm{p}=0.0012)$. Conclusion: Nearly one out of ten children suffers from hypovitaminosis D in the District of Parakou in 2017. The associated factors were age of child and mother, early weaning and mother's professional occupation held out of direct sunlight. This research work should be continued and improved by a nationwide multicentre study. This could lead to the adoption of measures for
\end{abstract}


hypovitaminosis D prevention among children in Benin.

\section{Keywords}

Hypovitaminosis D, Associated Factors, Children, Benin

\section{Introduction}

Nutritional rickets is the visible tip of the iceberg formed by diseases caused by hypovitaminosis [1]. In addition to its function in bone health and immunomodulatory effects on the immune system, vitamin $\mathrm{D}$ also contributes to protect against cancers as well as auto-immune, cardiovascular, metabolic and infectious diseases [1] [2]. Vitamin D plasma concentration is influenced by level of sunlight which is significant in Africa. This may justify the little interest granted to that micronutrient by the African scientists. In our environment, there are factors that impede the endogenous production of vitamin $\mathrm{D}$ in children. These are skin color, level of sun exposure, dress style and nutrition. In a study conducted in a temperate zone (New Zeland) among children in 2005, Rockell et al. had reported a prevalence of $35 \%$ [3]. Hypovitaminosis D is common among children both in temperate and tropical regions. For instance, in Nigeria in 2000, Tom et al. had reported a prevalence of $37 \%$ [4]. Besides, the relation between hypovitaminosis D and infant and child mortality in Africa should be considered. In Benin, a study conducted in Parakou on the plasma vitamin D profile in children hospitalized for severe malaria showed a frequency of $83.8 \%$ hypovitaminosis [5]. This raises the question of the interaction between this micronutrient and malaria on the one hand, and then others infectious diseases on the other hand in a country without any policy of Vitamin D supplementation under the pretext of a high level of sunshine. The purpose of this research work was to investigate hypovitaminosis D prevalence and its associated factors among children aged 6 to 59 months in the District of Parakou in 2017.

\subsection{Methods}

This research work was a cross-sectional study with prospective data collection performed within the community in the District of Parakou (Northern region of Benin). The study was carried out during the period running from May to July 2017. The study population consisted of all children aged 6 to 59 months and living in the District of Parakou for at least 6 months. On the other hand, the study excluded children suffering from acute malnutrition (Mild upper arm circumference (MUAC) $<125 \mathrm{~mm}$ or weight for height score lower than -2 standard deviation (SD) or nutritional edema). In addition, the study did not involve children with vitamin D supplementation underway or in the three past months. Eventually, this study did not include children tested as HIV positive. Moreover, those whose parents did not give their consent to participate to the study were 
also excluded. Sampling was probabilistic; it was carried out using a two-stage cluster sampling in accordance with WHO guidelines. Cluster unit consisted of one group of children aged 6 to 59 months living in an area of the District of Parakou. Statistical unit was represented by one child aged 6 to 59 months who meets the inclusion criteria. Areas were randomly selected; and cluster interval, number of clusters as well as number of children by cluster were calculated. Sample minimum size expected in the study was 321 (according to Schwartz formula), with an $83.3 \%$ prevalence of a study conducted in Tanzania in 2000 [6]. For each child involved, a "face-to-face" interview (interviewer/respondent) was performed to collect data among mothers or child minders using a survey form. The main variable of this study was hypovitaminosis D. Vitamin D level was defined as normal when it oscillated between 30 and $150 \mathrm{ng} / \mathrm{ml}$. A child was considered with hypovitaminosis when vitamin $\mathrm{D}$ concentration was lower than $30 \mathrm{ng} / \mathrm{ml}$. Vitamin D deficiency was retained when concentration was lower than $20.8 \mathrm{ng} / \mathrm{ml}$; deficiency was classified in two categories: moderate (between 12 and $20.8 \mathrm{ng} / \mathrm{ml}$ ) and severe (lower than $12 \mathrm{ng} / \mathrm{ml}$ ). A child was with hypervitaminosis D when vitamin D level was higher than $150 \mathrm{ng} / \mathrm{ml}$ [7]. Vitamin D plasma concentration was obtained through "radioimmunoassay" on plasma after blood collection among selected children. The blood thus taken into a dry tube was centrifuged to collect plasma which was stored at $-18^{\circ} \mathrm{C}$ during 1 to 2 months before being handled. Actual vitamin $\mathrm{D}$ screening test by means of radioimmunoassay was implemented in four phases which are extraction with acetonitrile, incubation, counting and finally reading of test results. The independent variables were economic variables, gynecological and obstetrical histories among mothers as well as sociodemographic variables, child care data, history of diseases and clinical data among the children. Entry and processing of data were carried out using softwares such as EPI INFO version 7.2 and SPSS 21. Measures of central tendencies and dispersion (Mode, Average, Standard deviation) served to describe quantitative variables. The ratios and their confidence interval were used for the description of qualitative variables. Ratios were compared using Karl Pearson's Chi-square test with a significance threshold estimated at 0.05 .

\subsection{Ethical and Professional Considerations}

The city council of Parakou, the heads of boroughs and chiefs of areas granted written authorizations for the conduct of this research work. The ethics committee of the Faculty of Medicine of the University of Parakou has approved it. Mothers and minders of the involved children had given their oral free and informed consent before any participation. The biological tests done within the framework of the study were fully free of charge for the participants. The refusal of a child mother or minder to participate to the study had no discriminatory effect. Children with hypovitaminosis D were treated free with an Ergocalciferol alcohol solution at a loading dose of 200,000 IU, followed by a maintenance dose of $1600 \mathrm{IU}$ per day. Cases of hypervitaminosis have not been treated. 


\section{Results}

A total of 502 children were shortlisted and four hundred (400) were finally involved in this study. One hundred and two (102) shortlisted children were not included in the study for many reasons: forty (40) were malnourished, twenty-one (21) were on poly-vitamin supplementation and forty-one (41) refused to participate to the study. None of the children was tested as HIV/AIDS infected. Figure 1 outlines the flow chart showing the source population and the study population.

\section{Population Description}

\subsection{Data Related to the Children}

Among the 400 children investigated, 192 were female (48.0\%) and 208 were male $(52.00 \%)$ i.e. a sex ratio of 1.08 . Mean age was $36.22 \pm 15.72$ months. The BCG vaccination coverage was $92.75 \%$ (29/400). Exclusively breastfed children were 283 i.e. $70.75 \%$. In this research work, weaning started before the age of six months in 203 children (50.70\%). Children weighed on average $12.8 \pm 3.09 \mathrm{~kg}$ with extremes ranging from 7 to $23 \mathrm{~kg}$. The average size of the children investigated was $87.89 \pm 12.51 \mathrm{~cm}$ with extremes oscillating between 55 and $115 \mathrm{~cm}$. In this study, weight for height (WFH) oscillated between -2 and 0 Z-score in

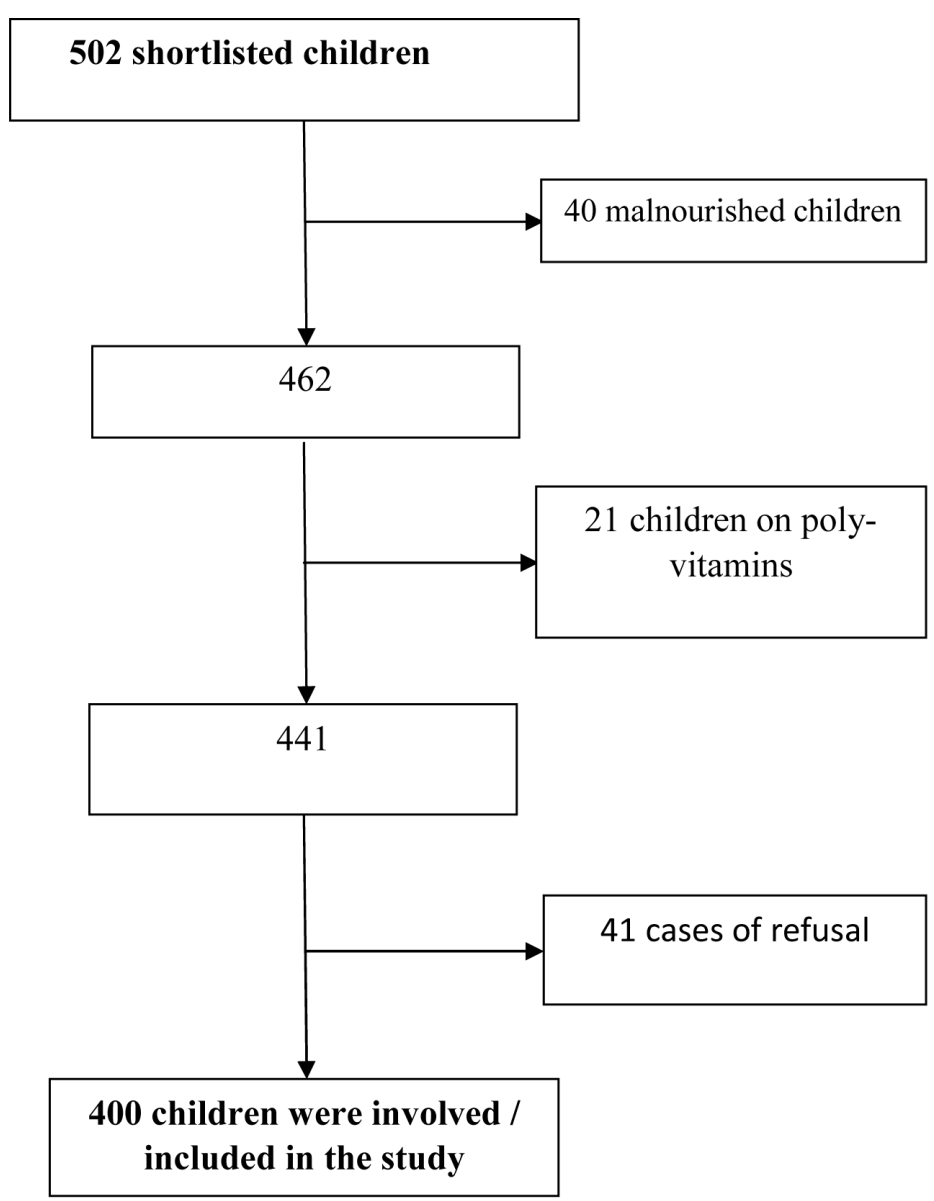

Figure 1. Flow chart showing the study population in Parakou in 2017. 
$47.50 \%$ of cases. Table 1 shows the distribution of children according to type of breastfeeding, weaning age and weight for height score.

\subsection{Data Related to Mothers and Child Minders}

Mothers' mean age was $28.20 \pm 6.13$ years with extremes ranging from 17 to 50 years. The predominant age group was the one varying between 20 and 29 years (63.75\%). Among them, 200 were uneducated (50.00\%). Two hundred and fifteen mothers worked in the sun (56.25\%) and 225 had a low socioeconomic status (56.25\%). Table 2 shows the distribution of mothers of involved children according to educational attainment, work place and socioeconomic status.

Table 1. Distribution of children involved in the study according to type of breastfeeding, weaning age and weight for height score in the District of Parakou in 2017.

\begin{tabular}{ccc}
\hline & Population size & Ratios \\
\hline Type of breastfeeding & 283 & 70.75 \\
Exclusive breastfeeding & 11 & 2.75 \\
Milk substitute only & 105 & 26.50 \\
Mixed & & \\
Weaning age (months) & 203 & 50.75 \\
$<6$ & 165 & 41.25 \\
$6-11$ & 20 & 5.00 \\
$12-17$ & 12 & 3.00 \\
18 & & \\
Weight for height (z-score) & 190 & 47.50 \\
{$[-2$ to 0$]$} & 210 & 52.50 \\
[0 to 2] & &
\end{tabular}

Table 2. Distribution of mothers of involved children according to educational attainment, workplace and socioeconomic status in the District of Parakou in 2017.

\begin{tabular}{ccc}
\hline & Population size & Ratios \\
\hline Educational attainment & 200 & \\
Uneducated & 4 & 50.00 \\
Literate & 80 & 1.00 \\
Primary school & 106 & 20.00 \\
Secondary school & 10 & 26.50 \\
Higher education & & 2.50 \\
Workplace & 215 & \\
In the sunlight & 185 & 53.75 \\
Out of the sunlight & & 46.25 \\
Socioeconomic status & 225 & \\
Low & 173 & 56.25 \\
Average & 2 & 43.25 \\
High & & 0.50 \\
\hline
\end{tabular}




\subsection{Vitamin D Plasma Level}

Among the 400 children involved in the study, 38 children suffer from hypovitaminosis D. Average plasma vitamin D concentration in investigated children was $71.07 \pm 39.43 \mathrm{ng} / \mathrm{ml}$ with extremes ranging from 11 to $227 \mathrm{ng} / \mathrm{ml}$. The average concentration of children with hypovitaminosis D was $24.05 \pm 4.86 \mathrm{ng} / \mathrm{ml}$ with extremes ranging from 11 to $29.90 \mathrm{ng} / \mathrm{ml}$. Two hundred and thirty-four children $(58.50 \%)$ had a vitamin D plasma concentration below the average $(71.07 \mathrm{ng} / \mathrm{ml})$. Figure 2 shows vitamin D plasma level in investigated children.

\subsection{Hypovitaminosis D Prevalence in Children Aged 6 to 59 Months}

Thirty-eight out of the four hundred investigated children had hypovitaminosis D i.e. a prevalence of $9.50 \%$. Among those 38 cases of hypovitaminosis D, there were 29 cases of vitamin D deficiency (7.25\%), eight children (2\%) had moderate vitamin D deficiency and one child $(0.25 \%)$ had severe deficiency. Besides, considering the threshold that defines vitamin $\mathrm{D}$ function outside the bones (50 $\mathrm{ng} / \mathrm{ml}$ or higher), the ratio of children unlikely to have the benefits of that micronutrient was $37.25 \%$. Figure 3 shows distribution of involved children according to their vitamin D status.

\subsection{Factors Associated with Hypovitaminosis D}

In this research work, child age and weaning age were statistically associated with hypovitaminosis $\mathrm{D}$, with respectively $\mathrm{p}=0.047$ and $\mathrm{p}=0.000$. Mothers' age

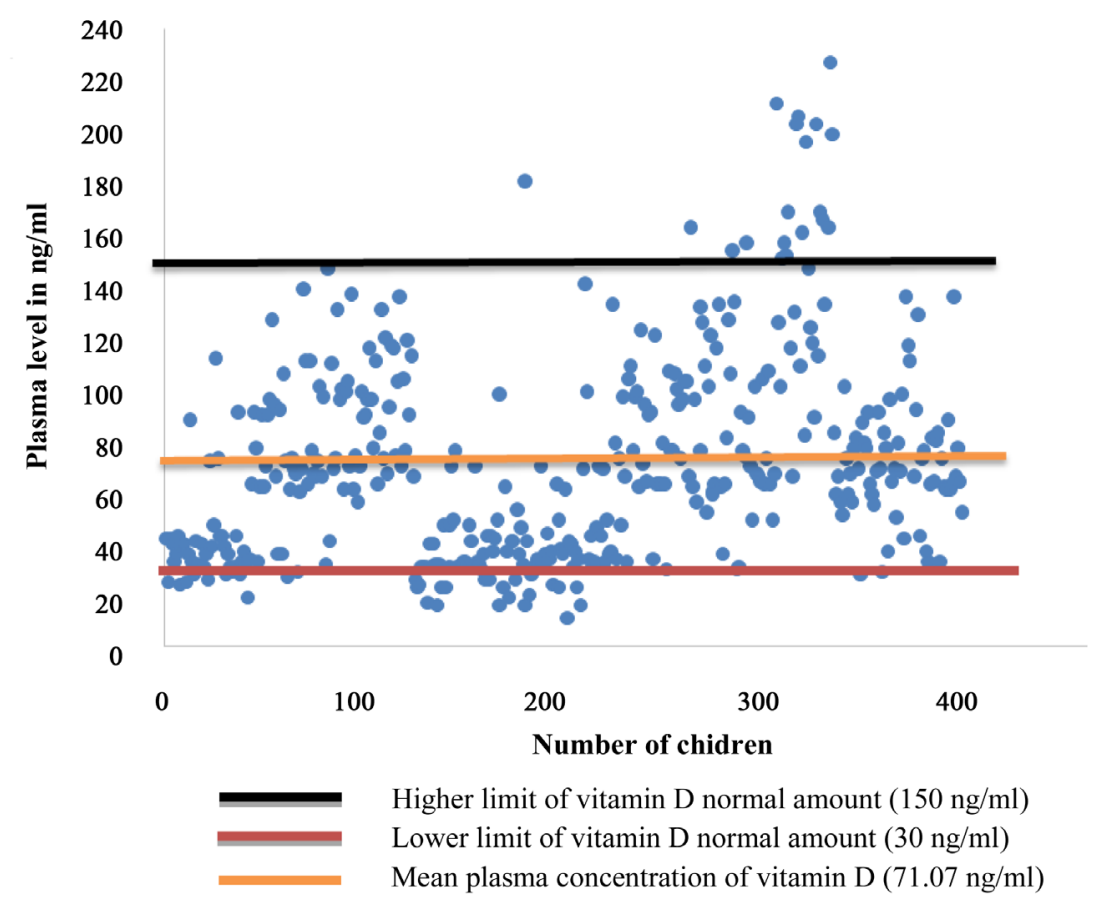

Figure 2. Vitamin D plasma concentration among 6 - 59-month children in the District of Parakou in 2017. 
and workplace were also associated with hypovitaminosis $\mathrm{D}$, with $\mathrm{p}=0.000$ and $\mathrm{p}=0.001$. On the contrary, the socioeconomic status and the weight-for-height score were not associated with hypovitaminosis. Table 3 indicates the relationship between hypovitaminosis $\mathrm{D}$ and sociodemographic data, data related to weaning age and nutritional status.

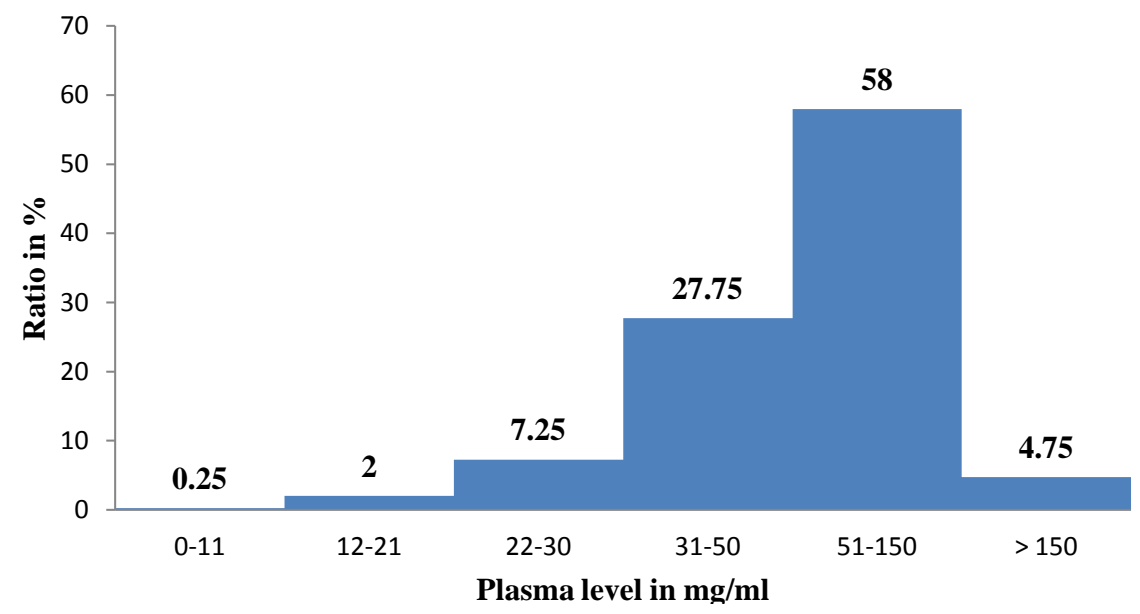

Figure 3. Distribution of involved children according to their vitamin D status in 2017.

Table 3. Relationship between hypovitaminosis $\mathrm{D}$ and sociodemographic data, data related to weaning age and nutritional status in 6 - 59-month children in the District of Parakou in 2017.

\begin{tabular}{|c|c|c|c|c|c|c|}
\hline & \multicolumn{5}{|c|}{ Hypovitaminosis D } & \multirow[b]{2}{*}{$\mathbf{P}$} \\
\hline & Total & $\mathrm{n}$ & $\%$ & RP & 95\% CI & \\
\hline Children' age (months) & & & & & & 0.047 \\
\hline $6-24$ & 119 & 6 & 5.04 & 1 & & \\
\hline$\geq 25$ & 281 & 32 & 11.38 & 2.41 & {$[1.02-6.50]$} & \\
\hline Weaning age (months) & & & & & & 0.0000 \\
\hline $6-11$ & 368 & 29 & 7.88 & 1 & & \\
\hline $12-18$ & 32 & 9 & 25.71 & 4.5 & {$[1.9-9.7]$} & \\
\hline Mothers' age (years) & & & & & & 0.0000 \\
\hline $17-29$ & 262 & 15 & 5.72 & 1 & & \\
\hline$\geq 30$ & 138 & 23 & 16.66 & 0.30 & {$[0.1-0.6]$} & \\
\hline Educational attainment & & & & & & 0.066 \\
\hline Uneducated & 204 & 14 & 6.86 & 1 & & \\
\hline Educated & 196 & 24 & 12.24 & 0.52 & {$[0.2-1.1]$} & \\
\hline Workplace & & & & & & 0.001 \\
\hline Exposed to sunshine & 215 & 11 & 5.12 & 1 & & \\
\hline Out of the sunlight & 185 & 27 & 14.59 & 3.16 & $1.5-6.6$ & \\
\hline Weight-for-height score & & & & & & 0.090 \\
\hline-2 to 0 & 190 & 23 & 12.11 & 1.7 & {$[0.9-3.5]$} & \\
\hline 0 to 2 & 210 & 15 & 7.14 & 1 & & \\
\hline
\end{tabular}




\section{Discussion}

The fact of not taking into account some diseases such as tuberculosis and malaria which are infections often associated with hypovitaminosis $\mathrm{D}$, may be a limitation of this study. However, its prospective character is a factor likely to limit missing data during collection. Blood collection and plasma sample conservation were performed under the conditions required for such a survey. Conservation time was short; this may help avoid a possible degradation of vitamin D. Vitamin $\mathrm{D}$ screening test was performed using radioimmunoassay. This technique has the advantage of being sensitive, specific, quick and quantitative. Its performance on children randomly selected within the community may help extrapolate the results on all the children aged 6 to 59 months in the District of Parakou.

\subsection{Prevalence of Hypovitaminosis}

Thirty-eight out of the 400 children involved in the study were suffering from hypovitaminosis $\mathrm{D}$. Mean plasma vitamin $\mathrm{D}$ concentration in deficient children was $24.05 \pm 4.86 \mathrm{ng} / \mathrm{ml}$ versus mean plasma concentration of all investigated children estimated at $71.07 \pm 39.43 \mathrm{ng} / \mathrm{ml}$. The mean vitamin D plasma concentration in deficient children found out in this study is similar to the one reported by Cusick et al. $(25.3 \pm 7.10 \mathrm{ng} / \mathrm{ml})$ in Uganda in 2014 among children aged 18 months to 12 years [8]. In Tanzania, Rwebembera et al. have reported in their study on 6-month children in 2013 a mean plasma concentration of $23.70 \pm 8.10$ $\mathrm{ng} / \mathrm{ml}$ similar to the one identified in this research work [6]. It is lower than the one reported by Nabeta et al. in $2015(32.20 \pm 10.90 \mathrm{ng} / \mathrm{ml})$ in a study carried out in Uganda among 6 - 24-month children [9]. The prevalence of hypovitaminosis D in 2017 among 6 - 59-month children in the District of Parakou amounted to $9.50 \%$. A similar prevalence has been reported by Bener et al. in a study conducted in 2009 in Qatar among under 5-year children seen in community [10]. This prevalence is lower than the one reported in 5 - 35-month children (37\%) suspected of rickets by Thacher et al. in 2000 in Nigeria and by Rwebembera in 2013 in Tanzania among 6-month children exposed to HIV [6] [11]. Normally, given the high level of sunlight in the District of Parakou, hypovitaminosis $\mathrm{D}$ ratio among children should be very low and even null. This points out that there are factors which predispose that group of child population to hypovitaminosis D. These predisposing factors may be their dress style, history of early births, long hospitalizations, eating habits, duration of sun exposure and particularly skin pigmentation. As a matter of fact, in the study of Guardia et al. conducted in 2008 in the United States of America, the ratio of people presenting with vitamin $\mathrm{D}$ deficiency was significantly higher among children with black skin than children with fair skin [12]. Although it is a protective factor against sunburn, skin pigmentation is a major cause of vitamin $\mathrm{D}$ deficiency in children.

\subsection{Factors Associated with Hypovitaminosis D}

The study focused on 6 - 59-month children. Children's mean age was $36.22 \pm$ 
15.72 months. The age group predominantly vitamin $\mathrm{D}$ deficient was the one of children whose age was higher or equal to 25 months. As a result, the older children's age is the higher risk of hypovitaminosis D is; this may be due to susceptibility to infectious diseases and hygiene conditions which become poorer. In addition, as from that age group skin becomes darker and may thus represent a protective barrier against UV radiation necessary for endogenous synthesis of vitamin $D$. The difference observed was statistically significant ( $p=0.047)$. The same remark has been made by Fasih in a study on the assessment of hypovitaminosis D frequency among 1 - 5-year children [13]. On the contrary, in a cross-sectional study conducted in Argentina on 290 children, Hirschler et al. have highlighted lack of correlation between vitamin $\mathrm{D}$ serum level and child age $(\mathrm{p}=0.14)$ [14]. If children aged 25 months and above are more exposed to hypovitaminosis D contrary to the WHO data which suggest that infants are particularly exposed to that phenomenon, therefore vitamin $\mathrm{D}$ endogenous production is difficult among them due to skin color, dress style and other situations which are likely to impede UV wavelength through the skin [15].

In this research work, mother's occupation out of sunlight was associated with hypovitaminosis $\mathrm{D}(\mathrm{p}=0.001)$. The same remark has been made by other authors who pointed out a significant relationship between the duration of sun exposure and hypovitaminosis D. For instance, Bener et al. have found out in 2009 in Qatar among under 5-year children a significant correlation $(\mathrm{p}<0.05)$ between hypovitaminosis D and duration of sun exposure [10]. On the contrary, in the same country in 2016, Almehmadi et al. identified a lack of correlation between duration of sun exposure and hypovitaminosis $\mathrm{D}$ in a study on children, with an average duration estimated at 4 hours $(p=0.48)$ [16]. The significant relationship between mothers' professional occupation out of sunlight and hypovitaminosis $\mathrm{D}$ identified in this study may be due to the cultural behavior based on the fact that mothers carry their children on their backs while working.

The old age of mother or child minder higher or equal to 30 years was a significant determinant of hypovitaminosis $\mathrm{D}$ in this research work $(\mathrm{p}=0.002)$. This interaction involves many questions, especially whether old mothers provide more protection to their children against UV rays or practice a diet low in vitamin D.

The results of this study indicate that early weaned children were more prone to have hypovitaminosis $\mathrm{D}$, with a significant difference $(\mathrm{p}=0.046)$. This may mislead into assuming that breast milk is a protective factor against hypovitaminosis $\mathrm{D}$. This is not the case since breast milk is vitamin $\mathrm{D}$ deficient. Better still, risk for hypovitaminosis is four times higher in children weaned at 24 months of age than those weaned at 12 months of age. In addition, no child on milk substitute fortified with vitamin $\mathrm{D}$ had developed hypovitaminosis $\mathrm{D}$. Without wishing to make the promotion of milk substitutes regarding their vitamin D content, it may be suggested, subject to further studies, to consider implementing vitamin $\mathrm{D}$ supplementation among children on exclusive breast- 
feeding. This finding of our study is similar to the one reported by Atiq et al. in Pakistan in 1998 among 6-year children weaned at the age of 4 months, with significant statistical difference $(\mathrm{p}=0.01)$ [17]. This relataionship existing between early weaning age and hypovitaminosis $\mathrm{D}$ may be due to the fact that weaning food were vitamin $\mathrm{D}$ deficient.

\section{Conclusion}

Nearly one out of ten children suffers from hypovitaminosis D in the District of Parakou in 2017. The associated factors were age of child and mother, early weaning and mother's professional occupation held out of sunlight. These results indicate that despite the high level of sunshine in the Northern regions of Benin, hypovitaminosis D among children is a critical issue of great concern. Therefore, other nationwide surveys should be conducted in order to capitalize on and show the benefits of vitamin D in the national health policy. Moreover, those further nationwide studies will help adopt new preventive measures against hypovitaminosis $\mathrm{D}$ among children in Benin.

\section{Funding}

Funding has been provided by

- Research fund of the University of Parakou (Benin);

- The corresponding author.

\section{Conflict of Interest}

The authors have not disclosed any conflict of interest concerning this research work implementation and the process of publication of this paper.

\section{Authors' Contribution}

- All the authors have proofread this paper;

- Alphonse Noudamadjo has initiated this research work and was responsible for the protocol drafting and paper writing;

- Bakiou Babatoundé participated to the protocol drafting, data collection and report writing;

- Joseph Agossou was involved in the protocol drafting and paper proofreading;

- Julien Didier Adédémy participated to the protocol drafting and paper proofreading;

- Falilatou Mohamed Agbeille participated to the protocol drafting and paper proofreading;

- Gérard Kpanidja participated to the protocol drafting and paper proofreading;

- Abogbo Gibril participated to vitamin D screening test;

- Marcellin Kuassi Amoussou-Guenou participated to vitamin D screening test. 


\section{Authors' Agreement}

All the authors have agreed to submit this paper for publication.

\section{Acknowledgements}

The authors are grateful to

- The children involved in this study and their mothers for their participation

- The Chiefs of neighborhoods, the Heads of boroughs and the Mayor of the District of Parakou for their sincere involvement

- The Vice-Chancellor's Office of the University of Parakou, in charge of academic affairs and research, for making funding available.

\section{References}

[1] Holick, M.F. (2007) Vitamin D Deficiency. New England Journal Medicine, 357, 266-281. https://doi.org/10.1056/NEJMra070553

[2] Bahri, L., Sanhaji, L., Tayeb, Z., El Maataoui, O., Farouqi, B., Takourt, B., et al. (2013) Vitamin D and Immunity. Moroccan Review of Rheumatology, 23, 30-36.

[3] Rockell, J., Green, T.J., Skeaff, C.M., Whiting, S.J., Taylor, R.W., Williams, M. et al. (2005) Season and Ethnicity Are Determinants of Serum 25-Hydroxyvitamin D Concentration in New Zealand Children Aged 5-14 y. Journal of Nutrition, 135, 2602-2608. https://doi.org/10.1093/jn/135.11.2602

[4] Tom, T., Philip, F., John, P., Juliana, L., Christian, I. and Gary, C. (2000) Case-Control Study of Factors Associated with Nutritional Rickets in Nigerian Children. Journal of Pediatrics, 137, 367-373. https://doi.org/10.1067/mpd.2000.107527

[5] Noudamadjo, A., Adédémy, J.D., Agossou, J., Sagbo, G.G., Agbeille, F., Kpanidja, G., Assoklé, J. and Akpona, S. (2018) Frequency of Hypovitaminosis D in 6 - 59 Month Children with Severe Malaria in the Pediatrics Unit of the Teaching Hospital of Parakou (CHUD/BA) in Benin in 2016. Open Journal of Pediatrics, 8, 66-73. https://doi.org/10.4236/ojped.2018.81009

[6] Rwebembera, A., Sudfeld, C.R., Manji, K.P., Duggan, C., Aboud, S. and Fawzi, W.W. (2013) Prevalence and Risk Factors for Vitamin D Deficiency among Tanzanian HIV-Exposed Uninfected Infants. Journal of Tropical Pediatrics, 59, 426-429. https://doi.org/10.1093/tropej/fmt028

[7] Ozkan, B., Hatun, S. and Bereket, A. (2012) Vitamin D Intoxication. The Turkish Journal of Pediatrics, 54, 93-98.

[8] Cusick, S.E., Opoka, R.O., Lund, T.C., John, C.C. and Polgreen, L.E. (2014) Vitamin D Insufficiency Is Common in Ugandan Children and Is Associated with Severe Malaria. PLoS ONE, 9, e113185. https://doi.org/10.1371/journal.pone.0113185

[9] Henry, N., Josephine, K., Reuben, K., Agnes, K. and Sarah, K. (2015) Serum Vitamin D Status Children with Protein-Energy Malnutrition Admitted to a National Referral Hospital in Uganda. BMC Research Notes, 8, 418.

[10] Bener, A., Al-Ali, M. and Hoffmann, G.F. (2009) High Prevalence of Vitamin D Deficiency in Young Children in a Highly Sunny Humid Country: A Global Health Problem. Minerva Pediatrica, 61, 15-22.

[11] Thacher, T.D., Fischer, P.R., Pettifor, J.M., Lawson, J.O., Isichei, C.O. and Chan, G.M. (2000) Case-Control Study of Factors Associated with Nutritional Rickets in Nigerian Children. Journal of Pediatrics, 137, 367-373. 
https://doi.org/10.1067/mpd.2000.107527

[12] Guardia, G., Parikh, N., Eskridge, T., Phillips, E., Divine, G. and Sudhaker, D. (2008) Prevalence of Vitamin D Depletion among Subjects Seeking Advice on Osteoporosis: A Five-Year Cross-Sectional Study with Public Health Implication. Osteoporosis International, 19, 13-19. https://doi.org/10.1007/s00198-007-0456-3

[13] Fasih, Z. (2016) Evaluating the Frequency of Vitamin D Deficiency in the Pediatric Age Group and Identifying the Biochemical Predictors Associated with Vitamin D Deficiency. Pediatrics and Therapeutics, 6, 2. https://doi.org/10.4172/2161-0665.1000289

[14] Hirschler, V. (2013) Low Vitamin D Concentration among Indigenous Argentinean Children Living at High Altitudes. Pediatrics Diabetes, 14, 203-210.

[15] WHO (2011) Vitamin D Supplementation among Infants. Electronic Library of Evidence for Nutritional Action (Elena).

http://www.who.int/elena/titles/vitamind_infants/fr/

[16] Almehmadi, B.M., Fallata, E.M., Alqahtani, S.Z. and Al-Agha, A.E. (2016) The Effects of Physical Activity and Sun Exposure on Vitamin D Status among Children from Jeddah, Saudi Arabia. Journal of Pediatric Care, 2, 1.

[17] Atiq, M., Suria, A., Nizami, S.Q. and Ahmed, I. (1998) Vitamin D Status of Breastfed Pakistani Infants. Acta Paediatrica, 87, 737-740.

https://doi.org/10.1111/j.1651-2227.1998.tb01739.x 